\title{
The Development Specifics of the Professional Integration-Communicative Competence of Students in Pedagogical Universities
}

\author{
Natal'ya D. Koletvinova ${ }^{1}$ \\ ${ }^{1}$ Kazan Federal University, Kazan, Russia \\ Correspondence: Natal'ya D. Koletvinova, Kazan Federal University, Kremlyovskaya Street 18, Kazan, 420008, \\ Russia.
}

Received: October 24, 2014 Accepted: December 3, $2014 \quad$ Online Published: December 18, 2014

doi:10.5539/res.v7n1p154 URL: http://dx.doi.org/10.5539/res.v7n1p154

\begin{abstract}
The urgency of this problem is related to the lack of a development degree of the theoretical and practical areas of the humanities and the physico-mathematical disciplines integration, required for the development of the professional integration-communicative competence. The purpose of the research is to develop a framework-specific set of parameters of professional integration-communicative competence development of students in pedagogical institutes. The leading approaches to the study of this problem appear as the integration-communicative approach, and the creative approach. The article reflects the results of this work, in which the students have mastered the basics of implementing the integration relations of physico-mathematical disciplines of the cycle, learned how to organize intellectual communication of training and educating character, acquired the competence of the professional activities having adequate speech design. The article submissions may be useful for professional work of university professors and high school teachers.
\end{abstract}

Keywords: competence, analysis, generalization, synthesis, meta-language, parameter, integration relations, distinguishing features, speech factors, the specifics of speech design, the specialty language

\section{Introduction}

At present expansion of the problems of increasing the effectiveness of student learning, various proposals to adjust the strategies and tactics of the professional readiness of students, introduced by the scientific communities, create a fairly complete picture of the increased requirements for teachers' professional activities in a market economy, as well as the picture of modern education in general and of the substantive and procedural reforms challenges it faces (Zakirova, 2014).

However, despite the awareness of the importance of the timely set educational objectives, in the training of teachers of the new formation no fundamental changes have occurred (Andreyev, 2012; Vvedenskiy, 2003; Zeyer, 2005). Employers are expecting from teachers high performance tenure of modern innovative training and educational technology, of a variety of professional communicative competences.

Accordingly, under the circumstances, there is an urgent need to use the technology with a high degree of innovation in the pedagogical process, with a clear dominant interaction of theoretical and practice-oriented forms of learning, relevant to contemporary needs in education.

"The main vector of organizing such teaching process is the formation of professionally-competent higher school graduate able to solve various problems ..." (Afanasiyev, 2013). The scientific community considers the problem of developing the professional competence as ambiguous. These problems require analysis of new aspects of technologies, methods, principles, techniques, and approaches that allow determining the dominant elements in the professional competencies functioning.

The professional integration-communicative competence occupies a special place in the system of professional communicative skills, because it allows the bridge to the interaction, interconnection and interdependence both of all components of the educational process objects and of reality phenomena as a whole.

Development of students' integration-communicative competence in the context of determining the degree of interaction between different disciplines belonging to different cycles should be advantageously carried out using 
specially developed research and teaching complex of integration parameters that allows students' entry into the world of professional competencies at an early stage of learning.

\section{Methodological Framework}

Contemporary views of the scientific community on the problem of training teachers have a wide variety: the communicative approach, the system approach, the creative approach, method of intellectual communication, of the integration relations implementation, of contextual guesswork, of dialogized communication, the search method and others. They all are analyzed from the perspective of finding new aspects in them, which increase the momentum of the educational activity and of performance quality.

As a unifying element in the scientific and educational views of scientists and educators stands out a creative development and the desire to structure a learning process on the basis of self-organization, self-learning and self-development (Andreyev, 2013). A teacher who has mastered these personal qualities, who meets the requirements of modern society, will be in demand and competitive.

Improving the efficiency of professional training of students is directly related to comprehensive competency erudition of a teacher. Professional competences are considered as the main performance indicators of the activity, personality creativity of a teacher. Priority in the work of a teacher is to ensure interconnection and interaction of all components of the educational process, which allow to picture education in educational institutions as a harmonized world of joy of communication and gained knowledge.

\section{Results}

\subsection{Problems of Students' Professional Communicative Competence Development}

Professional activities of teachers in every field require full command of substantive-procedural speech parameters. Relations of the Russian language with the disciplines of physics and mathematics cycle have informative and textual, as well as functional orientation, being realized in the course of multi-level multifunctional activity of the teacher. The success of the various types of professional activities is determined by the degree of adequacy of their speech clearance in accordance with the teaching requirements of clarity, accessibility and interestingness.

Deriving features of the academic disciplines is related to the solution of certain problems. The first objective is a problem of physical and mathematical departments' students' awareness of the necessity of close attention to the word, to culture of speech in general.

The second objective is to determine the distinguishing features of physico-mathematical disciplines, correlated with the specifics of their speech processing, adequate to the objects, goals, objectives and methods of scientific knowledge.

The third objective is to derive indicators of the influence degree of physico-mathematical disciplines features on the nature of professional intellectual communication.

The fourth objective is to create special creative communicative tasks, reflecting features of physical and mathematical sciences, and to improve the professional integration-communicative competence of the teacher.

To solve the problems the following parameters were identified: the parameter of speech factors; the parameters of distinguishing features of disciplines; the parameter of contrastive comparison; the parameter of communicative and creative activities (Koletvinova, 2004). At all the stages of student learning assistance from the teacher on the basis of feedback should be traced (Race, 1993).

\subsection{The Parameter of Speech Factors}

In the first stage of professional training the features of the speech factors parameter were analyzed. It reflects the requirements of the speech processing of necessary activities of the mathematics teacher and the physics teacher, includes a variety of informative educational material, functional-semantic types of speech, information and verification statements, varied verbal clearance due to situational character, specialty language, meta-language, and others.

At the beginning of the work diagnostics of determining the level of vocabulary with the integration components in the context of the speech activity of a professional orientation was carried out, as well as of the level of psychological readiness of students to master professionally-oriented speech material. The diagnostics showed lack of the initial vocabulary and skills to compose sentences for professional speech activity. Accordingly, we developed a special range of formation types of professional speech activity, a series of communicative tasks, correlated with the development of the high activity of cognitive processes (Zimnyaya, 2005; Boström, 2013; 
Thomas, 2012). Priority at this stage is given to differentiation and adaptation technologies, to methods of integration relations implementation, communicative methods, reflexive methods, search methods, and others.

Specially designed cycles of tasks are divided into thematic situationally-dependent assignments, tests, questions for reflection. Students independently choose those activities that require the use of a variety of strategies, tactics, techniques and gain satisfaction in small research forms, gradually accumulating experience for future professional activities (McKenzie, 2001).

Development of students' self-dependence qualities becomes the main task of their professional training. And in the work attention is drawn to the fact that "critical thinking cannot guarantee the ultimate truth, but gives an alternative to making the right decision" (Austin).

Overall, the work at this stage is preparatory and rehearsal by nature and is seen as a creation of a kind of a data bank for further professionally-oriented work of a more complex nature.

\subsection{The Parameter of Academic Disciplines Distinguishing Features}

At the second stage the parameter of distinctive features of physical and mathematical sciences cycle is considered. It includes features of two types: of subject-dependent and communication-dependent, which are together in close interaction. Subject-dependent features: a) the particularities of mathematics or physics object; b) features of the goals and objectives of the sciences objects; c) methods, consistent with the objectives and tasks of the objects of physics or mathematics.

These features are dictated by the content of a scientific discipline, its functional orientation. This determines the differences in the choice of forms of presentation of educational material. On this basis, the communicative features of the disciplines of physics and mathematics cycle were derived: a) the subject-dependent distribution of the types of professional communication activities in the intellectual dialogue; b) compliance with the conditionality of unplanned situational types of professional communication; c) adjustment for the use of differentiated speech means in the process of professional communicative work of a mathematics teacher and physics teacher; d) adjustment for the pedagogical communication using relevant techniques, methods and tools for the transfer due to the content of physical and mathematical sciences.

At the second stage priority is given to the communicative skills technology status, to the differentiation of speech means technology, methods of creativity, implementation of integration relations, research method, reflexive method and others.

Students analyze the essence of the subject-dependent features and communication-dependent features arising in the context of their target and motivational systems, paying attention to the adequacy of their speech processing. Here the highest value is placed on the encouraging and supporting intrinsic motivation principle (Conner, 2006).

Development of professional integration-communicative competence is carried out in the implementation of situationally-determined tasks, tests, questions for reflection.

Replies and completed assignments are collectively analyzed and assessed, which promotes dialogized communication of professional orientation level (Kaminskaya, 2003). Dominant role in the evaluation of the answer is given to such components as self-education, self-actualization, self-determination, self-organization, and others. This is due to the development of needs in self-education and self-masterying necessary and sufficient professional competencies that meet the needs of the modern society (Implementation, 2010).

Students' understanding of the usefulness of the integration component as a factor in increasing the efficiency of the educational process is manifested in the performance of tasks to define the relationship and interaction of various content-informative and substantive-procedural materials, of theoretical and practice-oriented integration components of physics and mathematics, to define the interaction of methods, means and forms of education.

\subsection{The Parameter of Contrastive Comparison of Academic Disciplines in the Context of the Requirements for Students' Professional Integration-Communicative Competence Development}

In the third stage the focus is maintained on the contrastive comparison parameter. This parameter allows determining differences in the professional integration-communicative competence of the mathematics teachers and physics teachers in the process of intellectual communication.

Mathematical explanation has a form of arguments presentation based on the features disclosure of the mathematical object, its goals and objectives, based on the desire to teach students to consciously have a grip on methods of mathematical thinking. Arguments presentation includes dialogized form of intellectual communication, aimed at the development of cognitive independence and creativity of students. 
Special features of the professional integration-communicative competence of math teachers can be attributed to specific difficulties associated with the language of the science, as well. The language of symbols, figures and graphs is aimed at implementing the nominative function of the speech processing of certain activities of the teacher.

If we conduct a contrastive comparative analysis of the professional integration-communicative competence of the mathematics teachers and physics teachers, we can find some differences that are important for the professional integration-communicative competence.

Physics, as we know, is not an abstract science, which entails the use of sufficiently diverse linguistic resources in the process of intellectual communication. The object of physics, goals, objectives and methods also require certain conditions for intellectual communication. On this basis, the intellectual communication in physics classes will have its own peculiarities, its own speech means.

Speech processing of intellectual communication in physics classes includes use of the specialty language; special speech means of logical reasoning categories registration; dialogized form of communication; use of complex syntax constructions of cause and effect orientation.

In contrast to the language of mathematics the language of physics is more diverse and is not "tied" to the scientific style of speech, as the physics actually reflects the real processes. This phenomenon opens up great opportunities for the development of interest in the subject.

The development feature of the professional integration-communicative competence of a teacher is not only the transfer of subject knowledge, but also learning certain techniques, ways, methods using which future teachers will teach their students. In this sense, knowledge of the discipline characteristics of a particular cycle, their role in the mastery of the professional integration-communicative competence, will help the future teacher to correctly organize intellectual communication of training and educating character.

In the third stage in the process of practice-oriented professional activity the precedence is given to competence-emerging technologies, criterial technologies, technologies of interdisciplinary integration, a hermeneutic technology. A starting point for mastering the contrastive comparison parameter may be the development technology of research skills, the technology of comparative analysis, integration training. Mastering the professional integration-communicative competence is based on specially designed cycles of situationally-conditioned tasks, problem-thematic issues aimed at developing the students' cognitive independence. In the process of development of self-recognition qualities, students complete assignments that significantly contribute to the development of the integration relations implementation competence, of problem-oriented discourses (Sleeman, 1992). Intellectual communication requires mobilization of such cognitive components as attention, memory, association, perception, apperception, and others.

Apperception, according to J. Miller is used as a generic term to describe mental processes by which incoming information is related to the previously structured conceptual system what stimulates further development of cognitive independence of future teachers (Miller, 1990). Separation of the intellectual information into "a past" and a new part is included in the apperception principle of learning, plays an important role in the intellectual dialogue, allowing a comparison of existing and newly acquired knowledge in the context of integration relations (Prince, 1981).

In the course of intellectual conversations a comparative analysis is conducted, that is of the ways, forms and methods of the integration relations implementation in the professional work of the teacher. At this stage, it is advisable to carry out multi-level work on the mastering functional-semantic types of speech activity.

The kind of work as preparing and conducting a class on the chosen topic, is aimed at the development of competency components of intellectual initiative, creative search for integration relations of training implementation and aims at the process of a meaningful differentiation of the important and the unimportant in the substantive-procedural activity of the future teacher (Race, 1993). Each task is aimed at developing the integration-communicative competence and relevant personal qualities based on self-understanding of all the features of the integration communication.

\subsection{The Parameter of the Integration-Oriented Communicatively-Creative Activity}

In the fourth stage, students enter the phase of completing the development of the professional integration-communicative competence. Selecting and working out methods of competency indicators development are defined by the tasks of communicative and creative activities. At the content-information part of the stage the actualization of the subject-educational knowledge in the disciplines of physics and mathematics cycle is carried out. At the operational-activity part situation-dependent tasks are performed, students 
independently design them, answer problem questions. The work is carried out in the context of the integration-communicative competence formation. At this stage, game elements are widely used. They aim to develop the ability to establish integration communication in the learning process. An important place is given to conducting tests to determine the points of contact between objects, on the basis of which the nature of integration relations is determined, as well as conditions and means of implementing them.

\subsection{Test and Evaluation Aspect of the Professional Integration-Communicative Competence}

Control of the mastery of this competence is carried out in the test and evaluation part of the professional training of students. During the control check cliché samples are being used, as well as informative training complexes that contribute to systematizing the knowledge to develop the integration-communicative competence.

The criteria are the correct implementation of the integration-communicative competence potential, application of special disciplines sublanguage knowledge, developed skills to use it, the knowledge of integration relations types, the feasibility and appropriateness of their use, knowledge of the integration character terminology.

The used parameters not only determine the direction for the development of the professional integration-communicative competence of domain-specific nature, but also affect the choice of informative speech richness of a particular discipline educational material.

This choice is largely correlated with the capabilities to optimally improve independent thinking, develop students' research abilities, and make the most of the educational potential of the disciplines of physics and mathematics cycle.

Such approach to the formation of the professional integration-communicative competence is in the mainstream of the modern educational paradigm, in which the emphasis is transferred to the development of creative independence and students' spirituality.

\section{Discussions}

Analysis of research works on the development of the professional communicative competence has shown the diversity of scientific views on this issue, use of different approaches, a wide range of unsolved problems. Recently, a special attention has been paid to developing the professional communicative competence in higher education: certain communicative tasks have been analyzed, educational design and educational technologies (Leontiyev, 1986), the professional self-concept of the teacher (Rean, 1997), quite adequately the concept of socio-psychological aspects of teaching and education was considered. In the concepts of foreign scientists the development of the professional communicative competence was seen in terms of widespread use of cooperative strategies and tactics in the communication process and the realization of individual features of professionally communicating ones (Johnson, 1987). However, in all its fullness the problem of the professional communicative competence development has not yet been solved.

The basis of this article is the aspect of analyzing the development features of the professional communicative competence of non-linguistic faculties' students, that has not received due consideration.

We consider the development of the professional integration-communicative competence in the context of a wide use of integration relations of physics and mathematics cycle disciplines specific implementation in correlation with speech factors.

Accordingly, we developed a special framework set of parameters of the integration orientation. Each parameter has its own target and performs the appropriate functions in the development of the professional integration-communicative competence. Knowledge of the main indicators helps students master the fundamentals of the implementation of physics and mathematics disciplines' integration relations, develop skills to correctly organize intellectual communication of training and educating character, master the competence of professional activities with adequate speech design. The results showed the effectiveness of the used approaches and methods choice and their positive impact on the development of the professional integration-communicative competence. The article submissions may be useful for the professional activities of university professors and high school teachers.

\section{Conclusion}

The findings of the systematic and targeted professionally-oriented work results showed that the level of development of the integration-communicative competence of the students generally meets modern education requirements.

The students have mastered the necessary and sufficient parameters of the professional 
integration-communicative competence, realized the distinctive properties of the academic disciplines, learned to navigate in the priority technologies, methods, forms and methods of training in the context of the integration relations implementation requirements. The students demonstrated the mastery of various types of speech activity, of the intellectual communication basis, the mastery of dialogized communication with adequate speech design. The used methods, techniques, approaches and technologies were considered in the context of their educational and creative opportunities, as well as of their importance for the teacher's professional activity. Students' answers had evidence-based, reasonable, logical character; the design of the professional activities was carried out in accordance with the substantive and procedural requirements of the multifunctional activity of the teacher at the present stage.

This research led to the following conclusions: a systematic approach to the development of professional training of students has been implemented; the parameters for the development of the professional integration-communicative competence were derived; specific features of the academic disciplines, their distinctive characteristics were derived, as well as the relationship and interaction in the course of the teacher's professional work. Technologies, methods, tools and ways of establishing integration relations in various kinds of work were identified, and the development of self-dependence qualities in the context of current demands in training and education; the criterial validity of the integration relations choice of substantive and procedural nature was disclosed; the use of the communicative, the differentiated and the creative approaches in the professional training of students as determining ones in achieving the development effectiveness of the professional integration-communicative competence was analyzed.

\section{References}

Afanasiev, D. V., \& Gryzlov, V. S. (2013). Competence approach and credit-modular system of training. Higher education in Russia, 6, 11-18.

Andreyev, V. I. (2012). The retrospective and the predictive approaches to conceptualizing the subjective-oriented teacher education for creative self-development of students-Future teachers. Education and self-development, 5(33).

Andreyev, V. I. (2013). Systematics of pedagogical and didactic laws of integrative orientation for guaranteed education quality. Education and self-development, 3(37).

Boström, L., \& Hallin, K. (2013). Learning Style Differences between Nursing and Teaching Students in Sweden: A Comparative Study. International Journal of Higher Education, 2(1), 22-34.

Conner, M. (2006). Andragogy + Pedagogy. Retrieved from http://agelesslearner.com/intros/andragogy.html

Implementation of "Education and training 2010" work programme. (2010). Working group B: "Key Competences”. Key Competences for Lifelong Learning. A Europian Reference Framework. Retrieved from http://europa.eu.int/comm./education/policies/2010/doc/basicframe.pdf

Johnson, D. W., Johnson, R. T., \& Holubec, E. J. (1987). Structuring Cooperative Learning: Lesson Plans for Ts. Edina, Minn.

Kaminskaya, M. V. (2003). Pedagogical dialogue in the activities of the modern teacher. M.

Koletvinova, N. D. (2004). Characteristics of teachers' professional communicative skills. Higher education in Russia, 10, 27-29.

Leontiyev, A. A. (1986). The principle of communicative skills today. A foreign language at school, 2, $27-32$.

McKenzie, J. (2001). How Teachers Learn Technology Best. The Educational Technology Journal, 10, 6. Retrieved from http://fno.org/mar01/howlearn.html

Miller, G. A. (1990). Linguists, psychologists, and the cognitive science. Language, 66(2), $317-322$. http://dx.doi.org/10.2307/414889

Prince, E. (1981). Toward a taxonomy of given/new information (pp. 223-235). N.Y.: Radical pragmatics.

Race, Ph. (1993). Never mind the teaching_Feel the learning. SEDA Paper 80, June, Birmingham.

Rean, A. A. (1997). The category of "communication" in contemporary general psychology and personality psychology. In Psychological Science: Tradition, the present state and prospects (p. 70).

Sleeman, D. (1992). Intelligent Tutoring Systems. New York: Academic Press.

Thomas, G. P. (2012). Metacognition in Science Education: Past, preset and future considerations. In B. J. Fraser, K. G. Tobin, \& C. J. McRobbie (Eds.), Second International Handbook of Science Education (pp. 131-144). 
Springer, Dordrecht. http://dx.doi.org/10.1007/978-1-4020-9041-7_11

Vvedenskiy, V. N. (2003). Modeling the professional competence of teachers. Pedagogy, 10, 51-55.

Zakirova, V. G., \& Koletvinova, N. D. (2014). Paradigm of future primary school teachers' vocational training. Life Science Journal, 11(4), 441-447.

Zeyer, E. F., Pavlova, A. M., \& Symanyuk, E. E. (2005). Modernization of professional education: The competence approach. $\mathrm{M}$.

Zimnyaya, I. A. (2005). Educational psychology: A textbook for higher schools. M.

\section{Copyrights}

Copyright for this article is retained by the author(s), with first publication rights granted to the journal. This is an open-access article distributed under the terms and conditions of the Creative Commons Attribution license (http://creativecommons.org/licenses/by/3.0/). 